\title{
Study Abroad and Second Language Socialization
}

\author{
Oraib Mango \\ California State University, San Bernardino \\ Email: omango@csusb.edu
}

Received 18 January 2015; accepted 12 February 2015; published 16 February 2015

Copyright (C) 2015 by author and Scientific Research Publishing Inc.

This work is licensed under the Creative Commons Attribution International License (CC BY). http://creativecommons.org/licenses/by/4.0/

(c) (i) Open Access

\begin{abstract}
The purpose of the study was to investigate college Arabic students' perceptions of their experience during a short-term summer study abroad program to Jordan. In particular, the study sought to examine how study abroad affected the participants' academic and career choices as well as how they perceived their second language socialization and its influence on their competence in Arabic. Results revealed that the short term SA contributed to students' perceptions of gains in their linguistic and cultural skills as well as to their openness to the world and to other cultures. The experience also contributed to students' decisions to apply for SA scholarships, and to choose areas related to Arabic language in their future studies and careers. Learners experienced a sense of empowerment and satisfaction at their ability to steer their learning and flourished when they could make their own choices in a supportive setting.
\end{abstract}

\section{Keywords}

Study Abroad, Second Language Socialization, Arabic Language Learners

\section{Introduction}

Educators generally agree on the importance of providing students with quality international education that prepares them for active participation in the global community. And in the view of many foreign language teachers, that quality—for acquiring both language and cultural proficiency — can be achieved through L2 immersion. One way of providing such an immersion is through study abroad (SA) programs. In the past twenty years, the number of US student participants in SA has more than tripled (Institute of International Education, 2012) [1]. Short term programs in particular have been gaining in popularity (Castañeda \& Zirger, 2011) [2]. In the year 2010/2011, more than half of US students studying abroad (58.1\%) took part in short term programs, marking a $2.5 \%$ increase from the previous year. These programs were summer-long or 8-week or shorter in duration. The 
gain in popularity of short-term programs and of nontraditional destinations prompted Castañeda and Zirgerto refers to them as the "new" study abroad.

While many of the SA research studies in the LL2 field investigated students' linguistic gains after their sojourn abroad, researchers have stressed the importance of hearing students' voices to understand the meanings they make of their experiences abroad; students' perspectives "provide invaluable data that cannot be obtained through observation or testing", their "documentation, reflections, and recounts of what happened in their SA lives and within their minds are crucial to the understanding of their SLS (second language socialization)" (Wang, 2010: p. 57, parentheses added) [3].

In addition to the importance of understanding students' perspectives of their L2 socialization in the host country, it is equally important to investigate the impact of these experiences on the lives of learners who often perceive their SA as a great influence on their lives (for example Lewis \& Nisenbaum, 2005 [4]; Norris \& Gillespie, 2009 [5]; Long, Yemi, Purdy, \& Nakano, 2010 [6]; Jones, Rowan-Kenyon, Ireland, Niehaus, \& Skendall, 2012 [7]). Davidson and Lehman (2005) find that the "long-term impact of SA on personal lives and professional careers will undoubtedly remain the primary validation of study abroad learning” (as cited in Davidson, 2010) [8].

\subsection{The SA Program}

This study reports on the SA experience of students who enrolled in a Jordan travel-abroad program in which they studied Arabic in Amman, Jordan for the duration of five weeks in the summer. The data in the present study were collected from students who participated in the program from 2004-2009. The program was led by two faculty members from the same public university who also taught the Arabic language classes during the SA. Students could earn 6-8 credits by enrolling in courses equivalent to first or second year Arabic. Otherwise, they could sign up for an Independent Study and Arabic Culture course. In the summer, they would attend class for four hours from morning until noon five days a week and usually had the afternoons free to explore the area. The students stayed at a 4- or 3-star hotel in the heart of Amman in a residential area that was within a short walking distance of a popular shopping area where students had access to cafes, restaurants, bakeries, grocery shops, and retail stores.

\subsection{Research Questions}

The present study aimed at investigating students' perceptions of their SA experience, specifically in terms of the process of their second language socialization in the host community and the impact of the program on their LL and their academic and professional trajectories. Therefore the main research question for this study is the following:

What are the meanings that students made of their short term SA program in terms of its influence on their academic and professional plans and on their L2 sociolinguistic competence?

The question comprises two sub questions:

a) How did SA affect students' academic plans and professional career choices?

b) What are students' perceptions of their SLS experience and its influence on their LL2 during their SA?

\section{Literature Review}

\subsection{Research on Study Abroad}

Most of the research on SA programs has focused on the outcome of programs in terms of learners' language attainment, attitude, motivation, pragmatics, and cultural competence or affect (Wang, 2010) [3]. Many research studies have shown that SA contexts were more effective in increasing students' linguistic competence than language programs in home institutions, but research is inconclusive regarding the increase of motivation as a result of these programs (Allen and Herron, 2003) [9].

Some researchers have drawn attention to possible drawbacks to SA such as students isolating themselves from the host culture by grouping themselves together, "superficial" cultural contact and inadequate opportunities for language practice (Day, 1987) [10]. Wilkinson (1998) [11] studied the interactional experiences of four 
undergraduate women studying for a month in Valcourt, France. She found that the students encountered cultural misunderstanding, had a hard time connecting with their host families, and expressed frustration at not finding enough opportunities to interact meaningfully with native speakers. Their experiences affected their perceptions of their SA and "often led them to negative stereotyping of their hosts and to an increased tendency to congregate among themselves" (Wilkinson, p. 34) [11].

Allen and Herron (2003) [9], in line with Wilkinson (1998) [11], found that participants in a six-week SA in France faced difficulties adapting to cultural and linguistic norms of the host country. While the students' linguistic skills in listening and speaking developed significantly, the interactions with native speakers were a major source of anxiety for learners and many of them experienced "fear of negative evaluation" (p. 382). The students' attitudes toward learning the language or toward French speakers did not improve after their SA.

Other studies that looked into students' SA experiences yielded different results. Ingram (2005) [12] investigated students' experiences during a three-week stay in France as part of a third semester French course in their home institution. He found that students had a positive experience that influenced their desire to enroll in more French courses upon their return. Kitao (1993) [13] investigated the perceptions of Japanese students who went on a 5-week SA to the US and found that students believed there was an improvement not only in their language skills but also in their motivation and confidence. They also developed a positive view of Americans and the US. Similar results were found by Stitsworth and Sugiyama (1990) [14] who surveyed two groups of a total of nearly 700 Japanese teenage students who went on a 1-month study-abroad to the US. The results indicated that there was a positive change in the students' attitudes who reported becoming more "sociable, extroverted, self-confident, and independent” in comparison with the group who stayed in Japan. McLeod and Wainright (2009) [15] found that students who had successful experiences during their SA developed more self-confidence and were aware of changes in their self-perception as well as their perception of the world.

In terms of SA impact on career choices, the Institute for the International Education of Students conducted a 2002 survey of 17,000 participants in their programs between 1950 and 1999. Data indicated that the SA experience greatly influenced the career choices of two thirds of the participants and that half of them developed careers with global aspects (Norris and Gillespie, 2009) [5].

\subsection{Second Language Socialization}

The framework which underlies this study is one of Second Language Socialization (SLS), defined as "the process by which novices or newcomers in a community or culture gain communicative competence, membership, and legitimacy in the group” (Duff, 2007, p. 310) [16]. This process is mediated by language through interaction within the host community. Studies have shown that "language socialization, identity, and academic achievement are closely interconnected" (Atkinson, 2002) [17] with a close connection between learning how to navigate within a certain community and language learning ("language, culture, and cognition are interconnected") (Vickers, 2007, p. 622) [18].

The kind of relationships that students have with native speakers in the host culture combined with their "learner-specific personality traits" may determine the "degree of exposure and immersion in the TL and culture" (Spenader, 2008, as cited in Wang, 2010, p. 57) [3]. The conditions of the SA settings alone cannot explain the differences between students' experiences. It is equally important to look at "the disposition toward language learning that these same students adopted” (Kinginger, 2008, p. 107) [19]. Successful L2 interactions in a lowanxiety context can promote self-confidence and positive attitudes toward the target culture and in turn motivate learners to further interact with members of the host community. These conditions-low anxiety level, selfconfidence and motivation-according to Krashen (1988) [20] facilitate successful L2 acquisition. Moreover, according to Yager, learners' attitudes toward the host community and language "may affect their language contact and how they benefit linguistically from that contact" (as cited by Allen and Herron, 2003, p. 372) [9]. Because students can have different language socialization experiences and varied perceptions of these impactful experiences, the SLS framework can be very beneficial in understanding and interpreting the "often contradictory results of research on SA gains” (Wang, 2010, p. 57) [3].

\subsection{Students' Perspectives}

Research on learner perceptions has been concerned with how students see themselves and how they see their 
learning (Wesely, 2012) [21]. In line with most researchers, in this study, I make no distinction between beliefs and perceptions. I adopt Horwitz's view of beliefs as "student opinions on a variety of issues and controversies related to language learning" (Horwitz, 1988, p. 284) [22]. With the advent of sociocultural theory in the field of SLA, it has been recognized that "once beliefs (or metacognitive knowledge) turn into mediational means, these can have an effect on learners - or teachers - and their actions, and in the case of learners either enhance their learning of languages or prevent them from learning them” (Barcelos and Kalaja, 2011) [23]. Wang (2010) [3] emphasized the need for a "socialization perspective," calling for researchers to pay more attention to students' perspectives and the identity-related issues that they face during their SA experiences.

\section{Methodology}

\subsection{Data Collection}

The data for this study were collected in 2010 through an open-ended survey questionnaire and a follow-up focus group discussion. The survey was e-mailed to students who had participated in the Jordan study abroad (JSA) program between summer 2004 and summer 2009 and whose contact information was available to the researcher. The researcher received e-mail responses from fourteen out of a total of 43 students. (The low response was affected by the fact that students who had already graduated or no longer had access to their on-record email may not have received the questionnaire.) The focus group discussion had five participants, none of whom had responded to the e-mailed survey. Three of them had participated in the Jordan program. To stimulate a more insightful discussion, two more participants were invited who had not participated in this specific SA experience. One of them, Amy, had participated in a year-long study abroad to Jordan while Jessica had participated in a short-term study abroad to Alexandria, Egypt.

According to Jaeger (1998) [24], if the population is very small, then a large sample population (10\% - 25\%) must be selected in order to represent it well. Since in this study, 17 students out of 43 participants during 2004-2009 took part in this study and contributed to a sample size close to 40\%, it can be considered representative.

\subsection{Participants}

Fourteen students filled in the survey and e-mailed it back to the researcher. Eleven of these students ranged in age from 19 - 23, three students were between 30 - 40 years of age. Twelve of the participants signed up for the SA summer intensive classes after having finished first year Arabic in their home institution. Two students started their first year Arabic classes during the summer program and one was enrolled in the culture class in addition to the independent study class.

None of the participants in this study were heritage learners. Nine were female and five were male students. At the time of the study, the university neither offered a minor nor a major in Arabic. However, students could choose to sign up for a certificate of Arabic language. Two of the focus group discussants, John and Aaron, had participated in the program in 2007, and Leo had participated in 2009. The other two participants, Jessica and Amy, had been on different SA programs. As mentioned above, their participation aimed at eliciting more discussions and exchange of ideas.

\subsection{Data Analysis}

Keeping all the research questions in mind, I borrowed analytic methods from grounded theory (Glaser and Strauss, 1967) [25] to "open-code" and find patterns between categories. I read every line of the data and jotted down concepts that the data may be referring to. I then went back and looked for all instances of each category; I compared between them and then wrote memos of the relationships between these categories and their meanings. That process resulted in combining some categories and redefining others. I then looked for patterns by examining contextual processes, causes, and conditions in order to reach propositions and connections (Behrens \& Smith, 1996) [26]. Discursive analysis was also used to examine the data from both the surveys and the focus group discussion. The analysis of the data from the open-ended surveys was informed and triangulated with the students' feedback from the focus group discussions. In order to help the readers track the analysis and establish its validity, excerpts from students' responses are provided for the assertions that were reached. 


\section{Results and Discussion}

\subsection{Effect of SA on Students' Academic Plans and Professional Career Choices}

All the students (through the survey and the focus group discussion)—in accordance with other research studies-indicated that the SA program was important in their lives. In terms of the effect that the program had on students' academic and career plan decisions, eleven out of the fourteen surveyed students and all of the five focus group students (84\% of the participants) reported that their SA experience influenced their academic and career plan decisions. Their SA had a direct influence on decisions they made regarding the following: a) choice of future field of study in graduate school; b) choice to continue studying the language; and c) decision to apply for study-abroad grants and internships.

Seven of the students applied for graduate schools in a field where Arabic can play an important role. These fields include: Arabic and Middle Eastern Studies, Global Studies and International Business/Relations.

The language and the culture motivated me to continue, to continue a master's degree in international peace that's focused around the Arab World and I hope, hopefully I can use the language too to continue it to pursue a career in that region. (Aaron, focus group)

Two additional students, who had not yet applied for graduate programs, expressed their intent to apply to programs in the same fields. All but one student reported continuing their studies formally and on their own during the year after SA. Eleven out of the 14 surveyed students, and all focus group participants reported taking Arabic in a formal setting (classroom) after the Jordan SA program (82\% of the JSA students, and $84 \%$ of all student participants). Two of the 14 students reported studying Arabic on their own using software and corresponding with Arabic speakers.

In terms like of only Arabic, it definitely made me want to study the language more and I came back and I took another year of Arabic. (Leo, Focus Group)

Seven students (50\% of JSA students) reported applying for scholarships and grants to study Arabic abroad after the program was over. Grants and scholarships included NSEP, Fulbright, and CLS. Of the seven students who reported applying, five were awarded these grants/scholarships. Aaron, one of the focus group JSA participants was awarded an internship after the program (see excerpt below). Thus, out of 17 JSA participants, eight students had applied to scholarships and internships after the program. Three more students expressed their intention to apply for future internships/scholarships for SA.

My study abroad in 2009 inspired me to pursue a career not only at the international level but in the, you know, in the Middle East and the Arab World. And you know like that that particular trip inspired me to apply to internships in that area and like I got one to Kuwait and I was able to utilize the Arabic speaking skills that I had and you know make relationships so, that particular experience was my first international experience too so, I mean that's, it was just a wonderful exposure to a different culture besides (name of state). (Aaron, survey)

\subsection{Students' Perceptions of their of SLS and Its Influence on Their L2 Competence}

1) All students perceived their daily interactions within the host community as an important part of the program, "I feel that the daily interaction was the real value of the trip" (David, survey). Out of a total of 19 students (14 surveyed and 5 focus group discussants), 15 mentioned that they used Arabic for their daily needs and interactions that ranged from talking with cab drivers to shopkeepers to servers at restaurants and employees at the hotel as well as to make conversations with local Jordanians.

2) Participants viewed SLS as a medium of enablement and autonomy. Socialization within the host community allowed students to be aware of their ability to control their LL and freely make choices and decisions that could enhance their learning experiences. This is perhaps the most important finding in this study. It reflects aspects of agency. Participants perceived their SLS as exciting and empowering. They talked of their social experiences using words signaling empowerment and self-confidence. Their use of first person pronouns was an indication of their own agency in controlling the socialization process.

I used Arabic as much as I could throughout all the daily interactions I had. That was probably the most 
exciting part of the trip because from cab rides to ordering lunch I'd try and speak it. (Robert, survey)

We were able to speak with shop keepers and with local people (Mary, survey)

The reassurance in my skills, being able to converse with people gives you the ego boost that you don't allow yourself even after studying Arabic for years at an American University. (Shana, survey)

Students expressed excitement and a sense of adventure regarding their abilities to use the language outside the confinement of the formal classes. Their socialization was also a motivating factor in prompting more interaction and L2 use.

Shana, in the excerpt below had a positive attitude toward socialization in the target culture and enjoyed the excitement of successful communication in Arabic while maintaining a positive attitude even when misunderstanding occurred. This positive attitude contributed to her successful SLS.

Going out to eat, getting into a taxi, buying something or just walking around were a complete adventure because you never knew what person you may be speaking to later or what words they might use which you may be unfamiliar with, but it was exciting when you spoke to someone and understood all or even bits of what they said. If you didn't understand or they didn't understand you, then you just laughed and apologized. (Shana, survey)

The following excerpt also exemplifies the sense of accomplishment and excitement at the learners' abilities to enhance their learning outside of class. Robert, in the following excerpt announced that the interactions that he embarked on were "probably the most exciting part" of the trip.

I used Arabic as much as I could throughout all the daily interactions I had. That was probably the most exciting part of the trip because from cab rides to ordering lunch I'd try and speak it. (Robert, survey)

In the following excerpt, Jessica's excitement about using the language is apparent in her amazement at being able to communicate in Arabic. Here, again, there is a comparison between the classroom and the outside interaction as the outside use gave her excitement and belief in her ability, implicitly indicating an experience different than the classroom one.

I think it helps being able to use it because until then it was just in the classroom and it didn't really feel like I could apply it that much? And then actually being there "Oh my gosh! I can actually use it, this works!” so I think that was a good experience learning that. (Jessica, focus group)

It [interaction] also provided more motivation for continuing studies because it made the desire to interact more fluently more real (Nancy, survey)

The experience allowed participants to direct their learning, make decisions, and gain access into the community:

a) Directing their learning. Students valued taking charge of their learning and credited their out-of-classinteraction with locals as the main reason for their perceived L2 development. They implicitly and/or explicitly put more value on that interaction than on class instruction.

I would say that the opportunity to speak with native speakers was the most helpful for me in advancing my

Arabic skills. The coursework was great as we moved so quickly through the book, I very much appreciated the intensive approach, but my time reading Arabic outside of the classroom on billboards, road signs as well as speaking with native speakers were most helpful in advancing my Arabic skills. (Karen, survey)

While most students credited outside interaction as more influential in their learning than the classroom, some found that a combination of both was essential while four of them-two JSA-found that the class was not beneficial and that interaction outside class alone or combined with colloquial classes would have been enough.

b) Making decisions. Students expressed that using the language and pushing oneself to "be out there" was a decision that they themselves made. All the students in this study - even the ones who did not use the language daily - realized the importance of interacting with members of the host culture. This disposition to language use can be significant in the success of SA programs (Kinginger, 2008) [19]. This was apparent in the surveys as well as in the focus group discussion. This had two sides to it: 1) pushing oneself to speak Arabic because in 
certain contexts, no one around them spoke the language; 2) choosing to use Arabic and socialize with locals in spite of the ease of using English in some contexts.

I did use Arabic in my daily interactions and this was a very valuable experience. However, the experience is what you make it, you can choose to use as much or as little Arabic as you would like given that in and around many of the places in Amman many people speak English. (David, survey)

It was very easy, especially in Amman to get by with just using English, and it seemed that a lot of the local nationals wanted to use English as much as possible (perhaps for their own practice) but if you tried most people would humor you and many seemed to be impressed that we were trying to learn Arabic. (Paul, survey)

Jessica, who went on a short term SA to Egypt, explained why she viewed her interaction during SA an important factor in learning Arabic; she pushed herself to understand others and to be understood because there was a need to communicate with her host family especially the 6 year-old child in the host family.

so like I had to figure out like I'm like no I have to figure out what this means and this means so I can talk to her about this so that would definitely help. (Jessica, focus group)

c) Gaining access into the community. Students were aware that SLS allowed legitimacy and access into the host community. They realized the importance of using the language as a mediation tool to gain acceptance in the culture. Students fondly mentioned how the people they met not only accepted them but also appreciated and helped them.

I found that whenever I used Arabic with people who were unable to speak English, they were thrilled and shocked and seemed to have a newfound respect for me. It was like they would at first see only a privileged

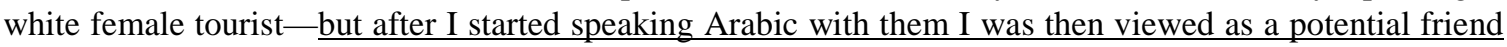
and someone to get to know. (Karen, survey)

Karen, in the excerpt above explained her awareness of the importance of language to gain acceptance and access into the host community as her language use afforded her to be looked at with respect and to be viewed as a "friend and someone to get to know".

Other students talked of valuable experiences of being welcome into homes of Jordanian families.

I became a welcome member of their family, visiting, trading Arabic lessons for English lessons with the kids, eating home cooked meals, watching the full moon rise, and discussing important aspects of Jordanian society with the women of the family. I have kept in contact with this family and hope to visit them again someday. (Tina, survey)

There was one family in particular that we made friends with that was generous enough to open up their home to our entire group. (Nancy, survey)

A few students expressed that they had kept in touch with Jordanians they met during the program. Nancy, quoted above even went back and visited again, "I have kept in touch with this family and have been lucky enough to go back and visit them twice since my original trip to Jordan with the program”.

3) Learners developed a positive look toward Jordan and Jordanians. They perceived their SA as a cooperative setting. Learners reported finding themselves surrounded by "kind" people who were impressed by their ability to speak the language and who were willing to speak with them in Arabic. As mentioned earlier, "language socialization is cooperative, reciprocal, and very complex" (Wang, 2010, p. 57) [3]. The socialization in this SA context allowed for cooperation between learners-new members—of the language community and expert community members who not only responded-in most cases-but also encouraged and gave value to the new members. In the excerpt below, Jessica indicated how when she spoke to taxi drivers, they were impressed and excited. The response and acceptance she got validated her as a legitimate new member and helped her have a "good" social experience.

People like it too I found. Cause I do a lot of stuff on my own. I'd start talking to the taxi driver and they're real excited they're like "where are you from?" and all this stuff and I'm talking in Arabic so it's like a good experience and it helps 
The following excerpts also showed students' positive perception of the setting and the host community

The people are very friendly and always helped us when we were trying to speak Arabic. (Mary, survey)

While the experience could be somewhat embarrassing for someone trying to, say, purchase a sandwich and explain to the salesperson in Arabic what kind of sandwich one would like, the people I met were more than willing to help one struggle through it. (Jenny, survey)

4) Beyond perceptions of language gains and membership into the community, the SA experience also had different influences on the learners' self-confidence and awareness of common human qualities and experiences. This agrees with the results found in other SA research studies (for example: Kitao 1993 [13]; McLeod \& Wainright, 2009 [5]; Stitsworth and Sugiyama, 1990) [27].

My experience abroad convinced me even more so how common we all are. The difference I would argue is geography, not state of mind. (Jackie, survey)

My perspectives did change after traveling to Jordan. I found I had much more in common with people around the world than I had ever thought. (Tina, survey)

It helped to show me that on a personal level most people were just interested in living and conducting business. (Paul, survey)

Traveling to Jordan and having the opportunity to study there not only alleviated many of these fears, but it also reinforced how important the opportunities are for us to interact with each other as people. (Nancy, survey)

In addition to their awareness of the commonalities between people, participants also reported more self-confidence and ability to deal with new and unfamiliar situations.

Being abroad made me so much more comfortable like with, you just like, with myself in all sorts of different situations, like it's funny how like after having been in Jordan like in a completely foreign sessionstudying situation and everything, I become, like I obtained a kind of skill like coming back here and I am completely comfortable going to parties where I don't know anyone because like hey that happened before! (Leo, focus group)

Students also reported a positive attitude toward travelling and more enthusiasm about future travels to the Middle East and willingness to have more SA experiences.

It definitely changed my plans for study abroad. I definitely, I want to go back to Jordan um I mean I am gonna graduate next year so I still have a lot of time to figure out how to, I am going to do that. So I hope I can go back and I really want to. (Leo, Focus Group)

Jordan was a wonderful place and I would love to go back and visit again if given the chance. (Paul, survey)

\section{Conclusions and Implications}

The results of the study indicated that SA had a positive influence on students' perceptions of gains in their L2 linguistic and cultural skills as well as to their openness to the world and to other cultures. It offered these learners meaningful use of the L2, led to more understanding of the commonalities that exist between people, and influenced some of them to prepare themselves to take active roles on the international scene.

Students' perceptions of their L2 socialization during their short-term SA program to Jordan were overwhelmingly positive. Students, for the most part interacted daily in a supportive atmosphere that encouraged them to speak and use the language. The SLS experience motivated them to continue their LL, apply for SA scholarships, and to choose areas related to Arabic language in their future studies and careers. SA helped them gain more confidence and contributed positively to their openness to the world and feelings of empathy toward different people and cultures. Most significant is the sense of empowerment that learners experienced as a result. Their sense of satisfaction at the ability to steer their learning and reap the rewarding results—successful communication, excitement, and motivation-emphasized the power of learners' autonomy. 
While this study investigated the experiences of SA students for six group cohorts over a duration of six years, the study has limitations; it only focused on one country and one language. Therefore, it is important to note that one group's experience is not representative of students' attitudes and beliefs in different languages, levels or institutions (Rifkin, 2000) [27]. The most significant finding of this research is that students flourished when they had more control of their learning, and were able to make decisions in a supportive setting. When learners are allowed to participate in their learning and make choices, their motivation increases and learning happens (Theisen, 2013) [28].

This study calls upon institutions and educators to seek to provide more opportunities for SA and for including students’ voices in curriculum planning and implementation of SA programs.

\section{References}

[1] Institute of International Education (2012) Open Doors 2012 Fast Facts. http://www.iie.org/Research-and-Publications/Open-Doors

[2] Castañeda, M.E. and Zirger, M. (2011) Making the Most of the "New" Study Abroad: Social Capital and the Short-Term Sojourn. Foreign Language Annals, 44, 544-564. http://dx.doi.org/10.1016/j.system.2011.07.001

[3] Wang, C. (2010) Toward a Second Language Socialization Perspective: Issues in Study Abroad Research. Foreign Language Annals, 43, 50-63. http://dx.doi.org/10.1111/j.1944-9720.2010.01059.x

[4] Lewis, T.L. and Nisenbaum, R.A. (2005) Extending the Stay: Using Community-Based Research and Service Learning to Enhance Short-Term Study Abroad. Journal of Studies in International Education, 9, 251-264. http://dx.doi.org/10.1177/1028315305277682

[5] Norris, E.M. and Gillespie, J. (2009) How Study Abroad Shapes Global Careers: Evidence from the United States. Journal of Studies in International Education, 13, 382-397. http://dx.doi.org/10.1177/1028315308319740

[6] Long, S.O., Yemi, S.A., Purdy, R.W. and Nakano, K. (2010) Deepening Learning and Inspiring Rigor: Bridging Academic and Experiential Learning Using a Host Country Approach to a Study Tour. Journal of Studies in International Education, 14, 89-111. http://dx.doi.org/10.1177/1028315308327952

[7] Jones, R.S., Rowan-Kenyon, H.T., Ireland, S.M., Niehaus, E. and Skendall, K.C. (2012) The Meaning Students Make as Participants in Short-Term Immersion Programs. Journal of College Student Development, 53, 201-220. http://dx.doi.org/10.1353/csd.2012.0026

[8] Davidson, D.E. (2010) Study Abroad: When, How Long, and with What Results? New Data from the Russian Front. Foreign Language Annals, 43, 6-26. http://dx.doi.org/10.1111/j.1944-9720.2010.01057.x

[9] Allen, H.W. and Herron, C.A. (2003) A Mixed-Methodology Investigation of the Linguistic and Affective Outcomes of Summer Study Abroad. Foreign Language Annals, 36, 370-385. http://dx.doi.org/10.1111/j.1944-9720.2003.tb02120.x

[10] Day, J.T. (1987) Student Motivation, Academic Validity, and the Summer Language Program Abroad: An Editorial. The Modern Language Journal, 71, 261-266. http://dx.doi.org/10.1111/j.1540-4781.1987.tb00365.x

[11] Wilkinson, S. (1998) Study Abroad from the Participants’ Perspective: A Challenge to Common Beliefs. Foreign Language Annals, 31, 23-39. http://dx.doi.org/10.1111/j.1944-9720.1998.tb01330.x

[12] Ingram, M. (2005) Recasting the Foreign Language Requirement through Study Abroad: A Cultural Immersion Program in Avignon. Foreign Language Annals, 38, 211-222. http://dx.doi.org/10.1111/j.1944-9720.2005.tb02486.x

[13] Kitao, S.K. (1993) Preparation for and Results of a Short-Term Overseas Program in the United States. Bulletin of the Institute for Interdisciplinary Studies of Culture, 10, 107-118.

[14] Stitsworth, M.H. and Sugiyama, Y. (1990) International Youth Exchanges: Measuring Their Impact on Attitudes (Abstract). ERIC Database, ERIC Number: ED331775.

[15] McLeod, M. and Wainright, P. (2009) Researching the Study Abroad Experience. Journal of Studies in International Education, 13, 66-71. http://dx.doi.org/10.1177/1028315308317219

[16] Duff, P.A. (2007) Second Language Socialization as Sociocultural Theory: Insights and Issues. Language Teaching, 40, 309-319. http://dx.doi.org/10.1017/S0261444807004508

[17] Atkinson, D. (2002) Toward a Sociocognitive Approach to Second Language Acquisition. Modern Language Journal, 86, 525-545. http://dx.doi.org/10.1111/1540-4781.00159

[18] Vickers, C.H. (2007) Second Language Socialization through Team Interaction among Electrical and Computer Engineering Students. The Modern Language Journal, 91, 621-640. http://dx.doi.org/10.1111/j.1540-4781.2007.00626.x

[19] Kinginger, C. (2008) Language Learning in Study Abroad: Case Studies of Americans in France. The Modern Language Journal, 92, 1-124. http://dx.doi.org/10.1111/j.1540-4781.2008.00821.x 
[20] Krashen, S.D. (1988) Second Language Acquisition and Second Language Learning. Prentice Hall, New York.

[21] Wesely, P.M. (2012) Learner Attitudes, Perceptions, and Beliefs in Language Learning. Foreign Language Annals, 45, S98-S117. http://dx.doi.org/10.1111/j.1944-9720.2012.01181.x

[22] Horwitz, E.K. (1988) The Beliefs about Language Learning of Beginning University Foreign Language Students. Modern Language Journal, 72, 283-294. http://dx.doi.org/10.1111/j.1540-4781.1988.tb04190.x

[23] Barcelos, A.F. and Kalaja, P. (2011) Introduction to Beliefs about SLA Revisited. System, 39, 281-289. http://dx.doi.org/10.1016/j.system.2011.07.001

[24] Jaeger, R.M. (1998) Survey Research Methods in Education. In: Jaeger, R.M., Ed., Complementary Methods for Research in Education, American Educational Research Association, Washington DC, 449-476.

[25] Glaser, B. and and Strauss A.L. (1967) The Discovery of Grounded Theory: Strategies for Qualitative Research. Aldine, Chicago

[26] Behrens, J.T. and Smith, M.L. (1996) Data and Data Analysis. In: Berliner, R.C. andCalfee, D.C., Eds., Handbook of Educational Psychology, Macmillan, New York, 949-989.

[27] Rifkin, B. (2000) Guidelines for Foreign Language Lesson Planning. Foreign Language Annals, 36, 176-179.

[28] Theisen, T. (2013) What Are the Possibilities for “Student Voice” in the 21st Century? (President’s Message). Language Educator, 8, 7. 
Scientific Research Publishing (SCIRP) is one of the largest Open Access journal publishers. It is currently publishing more than 200 open access, online, peer-reviewed journals covering a wide range of academic disciplines. SCIRP serves the worldwide academic communities and contributes to the progress and application of science with its publication.

Other selected journals from SCIRP are listed as below. Submit your manuscript to us via either submit@scirp.org or Online Submission Portal.
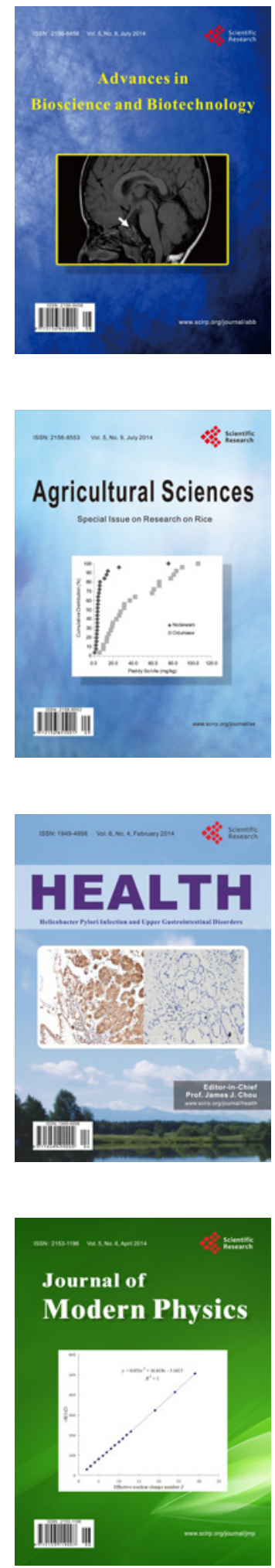
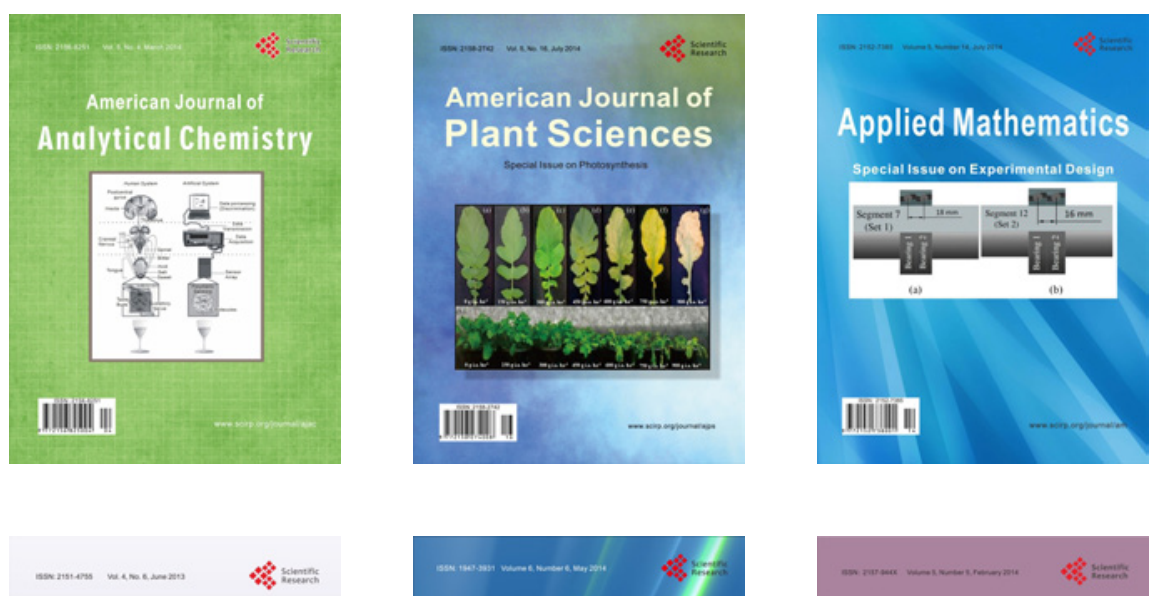

Creative Education
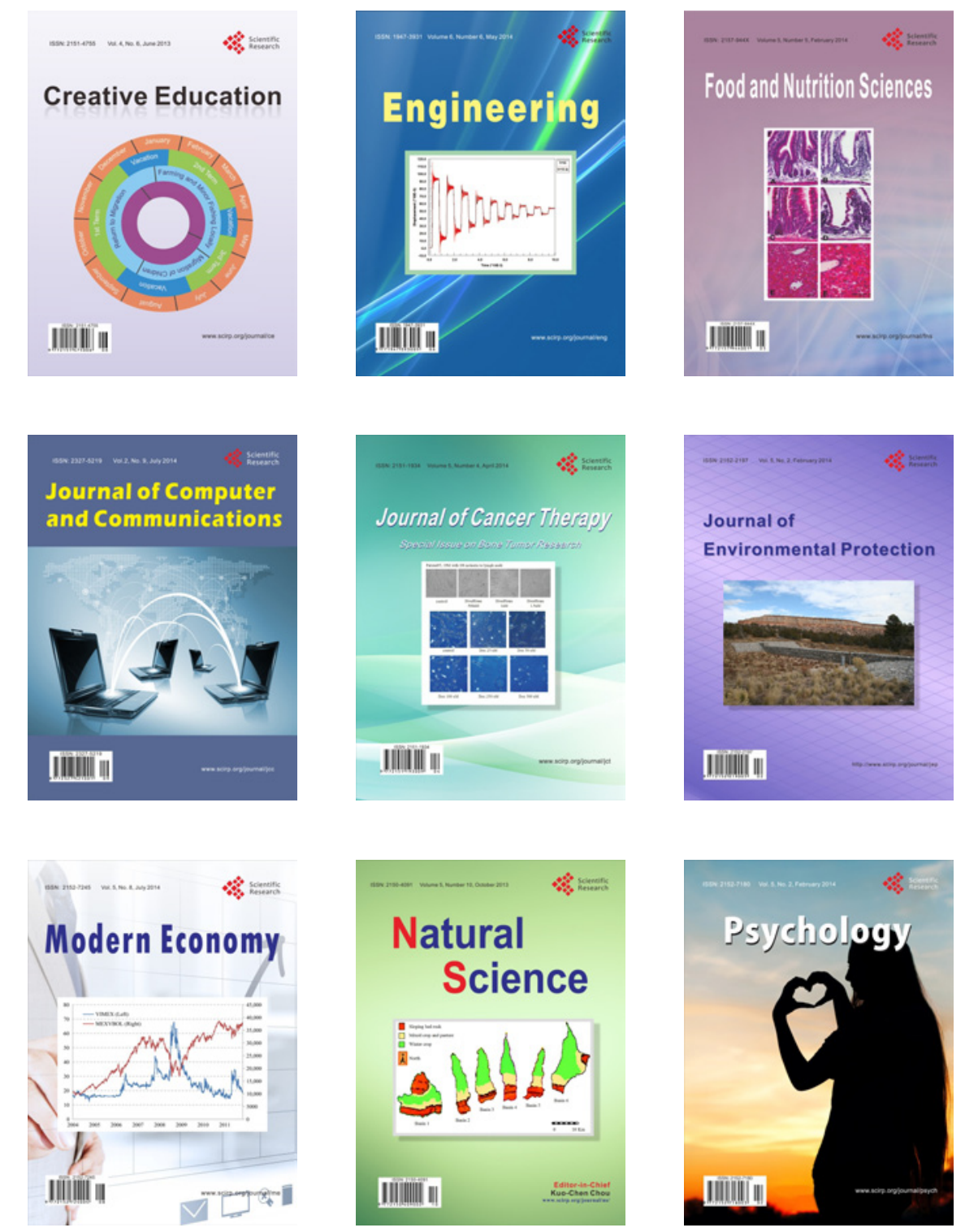